neofilolog

Czasopismo Polskiego Towarzystwa Neofilologicznego

ISSN 1429-2173, elSSN 2545-3971, 2020, NR 55/1, 11-26 http://dx.doi.org/10.14746/n.2020.55.1.2

http://poltowneo.org/

\title{
Jolanta Sujecka-Zajqc
}

Uniwersytet Warszawski

https://orcid.org/ 0000-0003-4903-0852

jolanta.zajac@uw.edu.pl

\section{Czy jesteśmy gotowi na ekoglottodydaktykę w polskim kontekście edukacyjnym?}

\section{Are we ready for eco-Foreign Language Teaching in the Polish educational context?}

The trend for eco-linguistics, which has been dynamically developing in the English-language literature since the 1970s, proposes a change in the perception of the relationship between language, nature, and culture, in a sense making language a link which brings together nature and culture, rather than separating them as is traditional. This approach poses important questions: How do languages work in the ecosystem created by the language environment of all users of a given language context? What relationships can they enter into? How should one perceive the development of multilingualism in such an ecological approach, in which not only does "strong" affect the "weak" but "weak" reciprocates? "Weak" has an important place in the language ecosystem, which risks serious changes due to excessive weakening of one of its components.

This paper aims to examine the possible inspirations that eco-linguistics offers Foreign Language Teaching (FLT), highlighting the role of each language and sensitizing the reader to the relationships that arise between languages and their users in a given environment. From this perspective Claire Kramsch (2008) postulates a change in the perception of the main function of the teacher from the "teacher of a code" to the "teacher of meaning", which has specific didactic consequences in how language activities are approached. Is the school classroom a place for activities which have their origin in the trend for eco-FLT? 
Keywords: eco-linguistics, foreign language teaching, language diversity, language environment, ecological-Foreign Language Teaching

Słowa kluczowe: ekolingwistyka, uczenie się/nauczanie języka obcego, różnorodność językowa, środowisko językowe, ekoglottodydaktyka

Terminy takie jak ekologia, ekologiczny zrobiły w ciągu ostatnich dwudziestu lat w dyskursie publicznym oszałamiającą karierę, głównie, niestety, za sprawą dramatycznie postępującej degradacji środowiska naturalnego oraz złowróżbnych przepowiedni o końcu świata w znanej nam dotychczas formie przyrodniczej i klimatycznej. Tendencje do rozważań w kontekście „eko" mają wszystkie dyscypliny związane z człowiekiem i jego wytworami, jednak pamiętajmy, że termin ekologia pojawił się w 1869 roku w biologii (Matczak, 2000: 12), a od początku XX wieku funkcjonuje jako samodzielna dziedzina naukowa badająca, zgodnie z etymologią greckiego oikos - dom, miejsce życia, organizmy w ich naturalnym 'domu', czyli środowisku. Celem niniejszych rozważań jest przedstawienie założeń podejścia ekologicznego dla nauczania/uczenia się języków obcych oraz próba udzielenia odpowiedzi na następujące pytania: Czy ekoglottodydaktyka stanowi interesującą, jakościowo odmienną propozycję dla badaczy? Czy jest możliwa do praktycznego wdrożenia i jeśli tak, to na jakich warunkach? W tym celu pokrótce przypomnimy punkty zwrotne w budowaniu uznanej już dzisiaj i osadzonej w licznej literaturze ekolingwistyki, a następnie przejdziemy do ekologicznych nurtów obecnych w glottodydaktyce (van Lier, 2004).

\section{Powszechność podejść ekologicznych w nauce}

Współczesne media uczyniły z ekologii dyżurny temat dnia, jednocześnie, jak to często bywa w takich przypadkach, spłycając samą dziedzinę do kilku nośnych haseł o mocnym zabarwieniu emocjonalnym. Profesor biologii i ekologii January Weiner z Uniwersytetu Jagiellońskiego zwraca uwagę na błędne nierozróżnianie w języku potocznym i dyskursie medialnym ekologii jako nauki i ekologii jako światopoglądu, a to są dwie różne kwestie: „W języku polskim pola semantyczne tego słowa [ekologia] całkowicie się pomieszały, więc musimy się umówić. Ja jestem ekologiem, a niezależnie od tego - ekologistą" (2019: 18). Ten pierwszy - wyjaśnia Weiner - "bada zmiany w przyrodzie”, a ten drugi „się nimi przejmuje” (tamże). Innymi słowy ekolog nie twierdzi, że należy chronić motyla niepylaka apollo, ale wie, jak to robić, gdyby ktoś (np. ekologista) zdecydował, że należy to robić. Ekologia jako nauka bada złożone relacje organizmów żywych ze środowiskiem zarówno z perspektywy pojedynczych 
osobników, jak i całych populacji. Badając relacje pojedynczych osobników ze środowiskiem, odwołujemy się do badań autoekologicznych, natomiast śledząc interakcje między osobnikami jednego lub wielu gatunków, wpisujemy się w nurt badań synekologicznych (Matczak, 2000: 12). Zanim termin ekologia przywędrował do językoznawstwa od początku XX wieku został już dobrze umocowany w wielu dyscyplinach naukowych, np. w ekologii społecznej (ang. human ecology) jako nurcie nauk społecznych ${ }^{1}$, w ekonomii ekologicznej oraz w ekologii kulturowej, w ekofilozofii i ekoetyce, w socjologii w ramach „analizy ekologicznej", w psychologii ekologicznej oraz w psychologii środowiskowej², w ekopedagogice, a także w geografii, w naukach politycznych oraz wielu innych dziedzinach w bardziej zawężonym zakresie (np. w etnologii czy w etnografii komunikacji). W ostatnim dwudziestoleciu interesuje także glottodydaktyków oraz, szerzej, specjalistów w zakresie edukacji.

\section{Ekologia języka vs ekolingwistyka - u źródeł terminologicznych}

Wychodząc z bardzo ogólnej definicji, według której przedmiotem zainteresowania ekologii jest funkcjonowanie organizmów w ich środowisku, szybko zorientujemy się, że to właśnie w ten sposób twórca terminu ekologia języka (ang. language ecology), amerykański językoznawca norweskiego pochodzenia Einar Haugen ${ }^{3}$ (1972), określał jego rozumienie w obszarze językoznawstwa jako: „badanie zależności między komunikacją językową a danym kontekstem środowiskowym, w jakim ma ona miejsce" (tłum. za: Krawczak, 2017: $149)^{4}$. W tym ujęciu ekologia języka jest wyłącznie specyficznym podejściem czy też specyficzną poddziedziną językoznawstwa, a twórca terminu od razu wyjaśnił, że środowiskiem języka jest społeczeństwo, które się nim posługuje jako jednym z kodów kulturowych oraz, że ekologię języka determinuje właśnie

\footnotetext{
${ }^{1}$ Termin ekologia społeczna został wprowadzony przez tzw. szkołę chicagowską. Nawiązując do nauk biologicznych, pokazuje ona analogie między światem biologii a światem społecznym, które łączą te same procesy konkurencji, dominacji oraz sukcesji (Matczak, 2000: 14). ${ }^{2}$ Tożsamość człowieka jest tutaj konsekwencją cech otoczenia społecznego i fizycznego. Zdegradowane środowisko ma bezpośredni wpływ na obraz samego siebie (staje się on uproszczony), na kod językowy (ograniczony) oraz na nasilenie patologii społecznych (Stadler, 1992, za: Matczak, 2000: 25). Według Tyburskiego (2017: 59), ,(p)sychologia ekologiczna analizuje nasze reakcje na sytuacje kryzysowe, pokazuje różne formy dostosowania się do wymogów środowiska, ale także adaptacji ludzi do zagrożeń. śledzi i analizuje ich dynamikę".

${ }^{3}$ Pogłębioną analizę pojawienia się terminu ekologia języka wraz z kontekstem jego utworzenia przez Einera Haugena możemy znaleźć np. w artykule Lechevrel (2010). ${ }^{4}$ The study of interactions between any given language and its environment (Haugen, 1972, tłum. za: Krawczak, 2017: 149).
} 
społeczeństwo, które się go uczy, używa i przekazuje innym osobom5. Peter M ühlhäusler, zadeklarowany zwolennik ekologii języka od lat 90. XX wieku podkreślał, że istotne jest uwzględnianie z jednej strony liczebności „współmieszkańców” danego ekosystemu (w tym przypadku języków), ale także, a nawet ważniejsze, jest uwzględnianie ustrukturyzowanych związków między owymi „współmieszkańcami" z jednej strony, a związków między poszczególnymi "mieszkańcami” a innymi czynnikami ekosystemu (M ühlhäusler, 1996, za: Costa, 2008, on-line).

Polem działania ekologii języka stały się zatem obszary naturalnie związane z cytowaną definicją: akwizycja języka drugiego, dwu- i wielojęzyczność czy różnorodność językowa. Dość szybko ekologii języka towarzyszy termin ekolingwistyki ${ }^{6}$, którym posługiwał się jako jeden z pierwszych francuski językoznawca Claude Hagège (1985: 146-147). Ekolingwistyka w jego zamyśle miała badać sposób, w jaki język uwzględnia w swoim systemie naturalne zjawiska ze swojego środowiska, takie jak cechy topograficzne terenu, relacje między ludźmi, innymi organizmami czy wręcz zjawiskami kosmicznymi. Innym pionierem francuskiej ekolingwistyki był Louis-Jean Calvet opisujący funkcjonowanie ekosystemów językowych w swoistych niszach ekologicznych, które są konstruowane w relacjach z innymi językami oraz miejscem danego języka w ogólnym ekosystemie (Calvet, 1999, za: Costa, 2008, on-line).

Ekolingwistyka uzyskała swój odrębny status naukowy w 1990 roku, najczęściej wiąże się ten fakt z referatem plenarnym M ichaela Alexandra Kirkwooda Hallidaya, New ways of meaning: The challenge to applied linguistics, wygłoszonym podczas IX Kongresu M iędzynarodowego Towarzystwa Językoznawstwa Stosowanego (ang. International Association for Applied Linguistics). Kolejne kongresy Towarzystwa uwzględniały już sekcję ekolingwistyki w swojej strukturze. Jej cele były definiowane trojako (Kramsch, Steffensen, 2008: 17):

- badania nad tym, jak język, na podobieństwo światła, odbija (ang. reflects), załamuje (ang. refracts) lub zniekształca (ang. distors) naturalne i społeczne środowisko;

- zastosowanie dobrze juz sprawdzonych teorii, takich jak krytyczna analiza dyskursu czy lingwistyka systemowo-funkcjonalna Hallidaya

\footnotetext{
${ }^{5}$ The true environment of a language is the society that uses it as one of its codes. (...) The ecology of language is determined primarily by the people who learn it, use it and transmit it to others (Haugen, 1972: 325).

${ }^{6} \mathrm{Na}$ gruncie francuskojęzycznym wahania terminologiczne są znaczne, badacze posługują się bardzo zróżnicowaną terminologią, obok écolinguistique znajdziemy także l'écologie linguistique, la linguistique écologique, l’écologie du langage, l'écologie des langues (por. Longhi, 2012).
} 
do analizy sposobów przedstawiania kryzysu ekologicznego od strony gramatyki i dyskursu;

- rozwój nowych teorii z uwzględnieniem podejścia ekologicznego w języku, gramatyce i dyskursie.

Jednak już w latach 90. XX wieku językoznawcy bardziej zainteresowali się tym, w jaki sposób sam język przekształca zjawiska naturalne, pytając czy działania językowe, w sposób dosłowny, wpływają na szanse przeżycia i dobrostan zarówno gatunku ludzkiego jak i innych gatunków żyjących na Zemi (Steffensen, Fill, 2014: 9). Twierdzącej odpowiedzi na to pytanie w wielu swoich badaniach udziela M ühlhäusler stosując podejście krytyczne do praktyk językowych i dokumentując degradujący wpływ tych ostatnich na naturalne środowisko człowieka. Jako przykład podaje wpływ języka angielskiego z epoki kolonializmu brytyjskiego na języki natywne plemion Australii i regionu Pacyfiku, który spowodował drastyczną zmianę u mieszkańców w sposobie podejścia do naturalnego środowiska: „ekosystemy o tysiącletniej historii wzajemnych powiązań pomiędzy ludźmi i ich naturalną ekologią zostały nagle zakłócone" (Mühlhäusler, 1996 za: Steffensen, Fill, 2014: 9)

\section{Cechy dystynktywne ekolingwistyki}

Badacze są zgodni co do tego, że kluczowym pojęciem ekolingwistyki jest holizm (Kramsch, Steffensen (2008: 18). Zgodnie z nim języki nie funkcjonują w wyizolowanych i autotelicznych systemach, ale są częścią naturalnego otoczenia, w którym wchodzą w relacje z czynnikami osobowymi, sytuacyjnymi, kulturowymi oraz społecznymi wpływającymi na ich ewolucję zarówno od strony ontogenezy, jak i filogenezy. Z tej konstatacji wynika szereg konsekwencji dla badacza-ekolingwisty (tamże):

- rygorystyczne uwzględnianie cech kontekstowych języka, które są zarówno osobowo-sytuacyjne jak i społeczno-kulturowe; w analizach pozostających w nurcie ekolingwistycznym należy zatem łączyć dane językowe z kompleksową całością ujmującą sytuacyjne umocowanie użytkownika języka wraz z cechami społeczno-ekonomicznymi i spoteczno-kulturowymi danego obszaru;

- podejście holistyczne wyklucza jakikolwiek redukcjonizm na wzór dualizmu kartezjańskiego, wszystko jest częścią niepodzielnej całości, a ekolingwista opisuje zjawiska językowe uwzględniając ich wzajemne połączenia, współzależność oraz interakcje;

\footnotetext{
${ }^{7}$ Ecosystems with a millennia-long history of coupling between humans and their natural ecology are suddenly disturbed (Mulhhauser 1996, za Steffensen, Fill, 2014: 9).
} 
- podkreślenie wartości płynącej z różnorodności; ekolingwistyka posługuje się modelem opisowym, w którym ważne miejsce zajmują cechy specyficzne, wyjątkowe, szczególne, a nie poszukiwanie uniwersaliów czy cech nadrzędnych, co ją odróżnia od socjolingwistyki czy analizy konwersacyjnej; zdaniem cytowanego już wcześniej M ühlhäuslera, kluczową właściwością każdego ekosystemu językowego jest ustrukturyzowana różnorodność (ang. structured diversity), w której nie tyle chodzi o siłę liczebności, ale o jakość istotnych znaczeniowo relacji; $w$ tym sensie wielojęzyczne społeczności, z wieloma "gatunkami” różnych języków, które nie wchodzą we wzajemne interakcje, nie mogą być postrzegane jako dobry przykład ekologii języka; niemiecki badacz wręcz określił, że w zdrowych ekosystemach językowych 90\% relacji międzyjęzykowych powinno być wzajemnie korzystne, a tylko niewielka ich część wchodzi w układy konkurencyjne czy eksploatacyjne (Mühlhäusler, 2002: 38 za Costa, 2008, on-line);

- podejście holistyczne prowadzi w stronę ogólnych teorii systemów, koncepcji systemów otwartych, emergencji i dynamiki nieliniowej; język odgrywa tu ważną rolę mediatora pomiędzy ekosystemem naturalnym i kulturowym.

Podsumowując powyższą charakterystykę, Kramsch i Steffensen (2008: 19) posługują się terminem dialogiczności, jako najwłaściwszym dla badań ekolingwistycznych. Powyższy obraz ekologii języka i ekolingwistyki jest zaledwie powierzchownym szkicem przemyśleń i badań w tej dziedzinie prowadzonych od ponad 40 lat (por. Steffensen, Fill, 2014; Chen, 2016) w wielu ośrodkach uniwersyteckich na całym świecie ${ }^{8}$. Jeśli jednak zastanawiamy się, czy jesteśmy gotowi w polskim kontekście edukacyjnym na ekoglottodydaktykę konieczne było wprowadzenie, choćby skrótowe, w sposób myślenia dotyczący języka w podejściach ekologicznych. W kolejnej części tekstu przyjrzymy się temu, co te ostatnie wnoszą lub mogłyby wnieść do nauczania/uczenia się języków obcych.

\section{Podejścia ekologiczne a glottodydaktyka}

Ekologia języka, która, przypomnijmy, stawia sobie za cel badanie funkcjonowania języka w jego szeroko rozumianym ekosystemie / środowisku, nie wydaje się być rewolucyjną zmianą dla myślenia glottodydaktycznego. Związki

\footnotetext{
${ }^{8}$ W Polsce bezsprzecznie prym wiedzie Poznańska Szkoła Ekolingwistyki na Uniwersytecie Adama Mickiewicza, która ma swój oryginalny wkład naukowo-badawczy w omawiane zagadnienia (cf. Krawczak, 2017).
} 
między sytuacją komunikacyjną a komunikatem są nam znane nie od dziś, współczesne teorie uczenia się bardzo mocno podkreślają rolę czynników zarówno indywidualnych, jak i społeczno-kulturowych w budowaniu wiedzy i kompetencji; wiele też czerpiemy z dziedzin ościennych, ważnych dla naszych badań: z socjoi pragmalingwistyki, psychologii kultury, antropologii czy socjologii.

W podobnym duchu wymiar ekologiczny wprowadzają do swoich rozważań nowo powstałe nurty ekopedagogiki oraz psychologii ekologicznej silnie powiązane z refleksją glottodydaktyczną. Ta pierwsza zwraca uwagę z jednej strony na wagę edukacji ekologicznej obejmującej wartości, uczucia, motywację, a także na rozwój sumienia ekologicznego oraz kształtowanie postawy proekologicznej obejmującej zmianę modelu konsumpcyjnego i stylów życia (Tyburski, 2017: 61); z drugiej zaś - na potrzebę radykalnej zmiany w myśleniu o systemie edukacji, w której to właśnie ekopedagogika będzie zadawała pytania „o fundamentalne zasady systemu społeczno-gospodarczego, w którym funkcjonujemy" (Walewicz, 2019: 61). Kontekstem takiego myślenia są prężnie rozwijające się nurty pedagogiki krytycznej i emancypacyjnej (Czerepaniak-Walczak, 2006; Giroux, Witkowski, 2010) odwołujące się do funkcjonowania człowieka w erze antropocenu i kapitalocenu (M oore, 2015, za: Walewicz, 2019: 61). Dalej jednak kluczowe pozostają następujące pytania: Co takiego przynoszą podejścia ekologiczne, czego nie wiedzielibyśmy z innych źródeł? Co oddala glottodydaktykę od ekologicznego myślenia? Odpowiedzi na nie udzielają zarówno eksperci w ekodydaktyce: van Lier $(2004,2010)$, Kramsch i Steffensen (2008), jak i pierwsi praktycy wdrażający ekologiczne zalecenia do swojej pracy w klasie (zob. Hahn, Rodriguez-Kaarto, 2015).

Zasadniczą trudnością glottodydaktyki zakceptacją podejścia ekologicznego jest trudność w holistycznym myśleniu o procesach językowych, o którym była mowa uprzednio. Oddzielanie elementów kognitywnych od społeczno-kulturowych jest mocno wpisane w tradycję myślenia i mówienia o procesach uczenia się. Ciągle jeszcze wydaje się, że z indywidualnego komunikatu językowego możliwe jest przejście do indywidualnego sposobu myślenia, gdy tymczasem „mowa nie odzwierciedla myśli, mowa „załamuje” myśli"9 (Volosinov, 1986, za: Kramsch, Steffensen, 2008: 22). Jak bowiem upewnić się, że twierdzenia wypowiadane w języku A, nie są odbiciem uwewnętrznionej socjalizacji danej osoby w języku B, C czy D? Takiego spojrzenia na proces akwizycji języka domaga się Larsen-Freeman w swoim tekście z 1997 roku (ibidem) ${ }^{10}$, w którym proponuje odwołanie się do

${ }^{9}$ Speech does not reflect thought, it refracts thought (Volosinov 1986 za Kramsch, Steffensen, 2008: 22).

${ }^{10}$ Larsen-Freeman, D. (1997), Chaos/complexity science and second language acquisition. „Applied Linguistics” 18(2), 141-165. 
sieci połączeń pomiędzy kategoriami takimi jak mikroskala pojedynczej osoby i makroskala w sensie społeczeństwa, pomiędzy dawnymi osiągnięciami a hipotetycznie możliwymi osiągnięciami w przyszłości, pomiędzy organicznymi i nieorganicznymi elementami uczenia się (komputery, podręczniki itp.), pomiędzy zachowaniem lokalny ma globalnymi wydarzeniami na świecie.

W ujęciu ekologicznym uczący się nie jest wpisany wyłącznie w tu i teraz swojego uczenia się, ale wnosi też pamięć poprzednich sytuacji uczenia się, plany przyszłych sytuacji uczenia się, subiektywną samoocenę i obraz swoich potencjalnych „ja” w przyszłości. Nauczyciele powinni pamiętać, że ich nauczanie obejmuje jednocześnie różne ramy czasowe: uczą nie tylko teraźniejszego nastolatka, ale także wcześniejsze dziecko i późniejszego dorosłego, toteż nie mogą ograniczyć się do tego, co aktualnie jest dostępne uczniowi, ale pamiętać o całym szeregu oczekiwań, możliwości i percepcji wpisanych w jego historię rozwoju.

Van Lier (2010: 3), holenderski badacz podejścia ekologicznego do uczenia się, wskazuje, że najważniejszym dążeniem podejścia ekologicznego jest patrzenie na proces kształcenia, na działania nauczyciela i uczą cych się, na wielowarstwową naturę procesów interakcyjnych i użycia języka uwzględniające całą ich złożoność oraz funkcjonowanie w sieci wzajemnych zależności osadzonych nie tylko w bezpośrednim kontekście, lecz także społecznym, fizycznym i symbolicznym ${ }^{11}$.

Odnajdujemy w tym opisie główne terminy ekolingwistyki: kompleksowość oraz sieć wzajemnych połączeń w szeroko rozumianym kontekście. W często cytowanej publikacji z 2004 roku ten sam autor wskazuje na kluczowe dla ekologii uczenia się elementy. Są to:

- relacje (ang. relationship), związki między ludźmi a światem na poziomie fizycznym, społecznym i symbolicznym;

- kontekst (ang. context) jako element definiujący użycie języka, jednocześnie sam podlegający wpływom językowym; w podejściu ekologicznym to sami uczestnicy uznają, co jest dla nich znaczącym kontekstem;

- jakość (ang. quality) przeciwstawiona standardom, które narzucają wysoki poziom wymagań, ale przyczyniają się do obniżenia jakości i życia, i nauczania;

- wartość (ang. value), ponieważ edukacja językowa jest nauką wartości, co przeciwstawia się kartezjańskiej dychotomii tego, co teologiczne i tego, co naukowe;

\footnotetext{
${ }^{11}$ An ecological approach aims to look at the learning process, the actions and activities of teachers and learners, the multilayered nature of interaction and language use, in all their complexity and as a network of interdependencies among all the elements in the setting, not only at the social level, but also at the physical and symbolic level (van Lier, 2010: 3).
} 
- krytyczna perspektywa (ang. critical perspective), która umożliwia nieustanne monitorowane tego, co się wydarza, zachęcając do krytycznego myślenia i działania;

- różnice indywidualne (ang. variability) w sposobie uczenia się, które każdy nauczyciel powinien uwzględniać, ale także różnice na poziomie makrosystemu, chociażby ze względu na to, że nie wszystkie szkoły spełniają ideał instytucji wyrównujących szanse społeczne;

- różnorodność (ang. diversity) rozumiana jako różnorodność osób, a ponadto zróżnicowanie języka rozumianego nie jako monolit, ale organizm, na który składają się dialekty, odmiany regionalne, odrębne zwyczaje kulturowe itp.;

- podmiotowość sprawcza (ang. agency), która przyznaje uczącemu się autonomię w działaniu oraz prawo do posiadania "własnego głosu" i własnego rozumienia swoich działań;

- emergentne struktury (ang. emergent pattern) wskazujące na nową jakość, którą poszczególne elementy uczenia zyskują funkcjonując jako całość.

Uzupełnieniem tej listy jest jeszcze jed no pojęcie, często przywoływane w opisach podejścia ekologicznego, a jest nim afordancja, termin zapożyczony od amerykańskiego psychologa Jamesa Gibsona (1986) i jego ekologicznej teorii percepcji bezpośredniej. Definiuje się je jako „wszystkie możliwości działania, na jakie pozwala środowisko" (Dotov i in., 2012: 282) lub inaczej jako to, "co środowisko oferuje zwierzęciu, z korzyścią bądź niekorzyścią. Mam tu na myśli coś, co odnosi się zarówno do środowiska, jak i do zwierzęcia, jednak nie istnieje żadne pojęcie określające taką relację" (Gibson, 1979: 127, za: Dotov i in., 2012: 284). Afordancje są okazjami do działania lub do jego zaniechania, które pojawiają się w chwili naszego wejścia w interakcję ze środowiskiem fizycznym lub społecznym. To, jak je wykorzystujemy, zależy od naszej indywidualnej percepcji sygnałów płynących ze środowiska. Ten sam zbiornik wody może być ofertą ugaszenia pragnienia dla jednych lub inspiracją malarską dla innych. Ucząc się, odkrywamy coraz to nowe afordancje oferowane przez różne środowiska, w których funkcjonujemy - dla języka może to być na przykład ton głosu, gest czy reakcja słowna.

Uczenie się języka w perspektywie ekologicznej jest więc nielinearnym, dynamicznym i złożonym procesem opartym na językowych afordancjach wynikających z reakcji uczącego się na jego interakcje ze środowiskiem (Järvinen, 2009, za: Hahn, Rodriguez-Kaarto, 2015, on-line). Odpowiadając na wyzwania związane z uczeniem się języka fińskiego przez imigrantów o wysokich kompetencjach zawodowych, mających trudności zintegracją właśnie z powodów językowych, 
specjaliści uniwersyteccy zaproponowali model uczenia się oparty na podejściu ekologicznym (Hahn, Rodriguez-Kaarte, on-line, 2015: 4), w którym wyróżnili następujące zasady i strategie projektowania kursu językowego:

\section{Zasady:}

- uczenie się J2 w działaniu i interakcji;

- uczestnictwo w lekcjach, które są wyzwaniem dla uczącego się;

- $\quad$ interakcje z 'bardziej kompetentnymi użytkownikami' (ang. M ore Knowledgeable Others);

- bezpośrednia i pośrednia percepcja środowiska oraz afordancje językowe;

- percepcja multimodalna i multisensoryczna;

- budowanie własnego "ja”.

\section{Strategie:}

- podstawa programowa oparta na działaniu;

- złożone zadania oparte na współpracy z'bardziej kompetentnymi użytkownikami';

- angażujące treści osadzone w zawodowo-kulturowych kontekstach;

- lekcje skontekstualizowane, uwzględniające różnice indywidualne uczących się;

- uczenie się oparte na zróżnicowanych środkach dydaktycznych i typach działań oraz przebiegające w różnych miejscach;

- demokratyczna, skłaniająca do czynnego udziału atmosfera lekcji;

- środowisko o wysokim stopniu semiotyzacji.

W celu jego realizacji wyróżnili cztery moduły zajęć (tamże: 4):

- moduł obserwacyjny (ang. observation-based learning module), w którym uczący się obserwują, obejmują refleksją oraz interpretują nagrania audio i wideo, teksty, autentyczne zdarzenia;

- moduł pisania (ang. writing-based learning module), w którym rozwijane są kompetencje pisania tekstów istotnych znaczeniowo dla uczących się (dzienników, pism formalnych, prezentacji problemów);

- moduł interakcyjny (ang. interaction-based learning module), podczas którego uczący się są zachęcani do podejmowania osobistych, akademickich lub zawodowych zadań w języku docelowym (np. zakupów, transakcji bankowych, prezentacji akademickich itp.);

- moduł mówienia (ang. speech-based learning module), w którym uczący się skupiają się na słuchaniu i ustnym reagowaniu rozwijającym słownictwo wokół materiału wideo (np. programu telewizyjnego); proponuje się odgrywanie scen, dyskutowanie, komentowanie itp. 
Analizując te propozycje, trudno mówić o zupełnie nowatorskim programie nauczania. Jest to raczej pewien sposób mówienia o działaniach, które, przynajmniej teoretycznie, nie są zaskakujące. Popatrzymy teraz na wskazówki dotyczące prowadzenia badań glottodydaktycznych w tak nakreślonym kontekście ekologicznym.

\section{Wyzwania badawcze glottodydaktyki w perspektywie ekologicznej}

Chcąc prowadzić badania uczenia się w podejściu ekologicznym, na co szczególnie zwraca uwagę włoski badacz tych kwestii Gabriele Pallotti (2002, online), należy bardzo starannie rozpatrzyć dwie kwestie:

1. dane zebrane do badania powinny być ekologicznie trafne, a zatem zebrane w warunkach możliwie jak najbliższych dla naturalnego kontekstu badanego procesu;

2. analiza zebranych danych ma na celu poszukiwanie systematycznych zależności pomiędzy cechami charakterystycznymi dla przebiegu uczenia się języka obcego a różnymi kontekstami, w które cały proces jest wpisany.

Takie postępowanie badawcze generuje szereg częściowo dobrze już znanych problemów metodologicznych (np. jak zebrać dane, nie ingerując w badane środowisko?) oraz teoretycznych: czym jest wspomniany kontekst? To pytanie było często analizowane przez badaczy ekologii języka, a próbą odpowiedzi na nie jest typologia powstała w ramach ekologicznej teorii systemów Urie Bronfenbrennera (1979, za: Pallotti, 2002: 166), który wyodrębnia cztery poziomy kontekstu:

- poziom mikrosystemu: zawiera wszystkie działania, role, funkcje właściwe dla danej osoby w jej bezpośrednim otoczeniu fizycznym i psycho-społecznym;

- poziom mezosystemu: odnosi się do funkcjonowania danej osoby w kilku mikrosystemach jej właściwych, dla dziecka, na przykład, to rodzina, szkoła, sąsiedztwo;

- poziom egzosystemu: nie dotyczy bezpośrednio danej osoby, ale to, co na nim zachodzi wywiera wpływ na jego funkcjonowanie w mikrosystemie, dla dziecka, na przykład, to miejsce pracy rodziców lub ich bezrobocie albo szkoła starszego rodzeństwa;

- poziom makrosystemu: silnie wpływa na trzy pierwsze poprzez odwołania kulturowe, ideologiczne czy gospodarczo-polityczne.

Niektórzy badacze dodają jeszcze chronosystem, ważny wymiar czasowy, o którym już wspominaliśmy wcześniej. 
Pallotti twierdzi, że samo uwzględnianie kontekstu w badaniach glottodydaktycznych nie jest nowością i to nie sama jego obecność definiuje podejście ekologiczne, ale miejsce, jakie mu się przyznaje. W jego przekonaniu perspektywa ekologiczna „polega na poważnym traktowaniu i systematycznym oraz pogłębionym rozwijaniu ogólnego i powszechnie przytaczanego twierdzenia, że 'kontekst jest ważny'. Kto chce zaangażować się w podejście ekologiczne do języka obcego, czyni z opisu kontekstu i jego związków z procesem akwizycji centralny przedmiot swoich badań"12 (Pallotti, 2002: 167). Język jest jednym z wielu elementów kontekstu i wobec tego produkcja wypowiedzi w języku obcym nie jest jedynym celem uczenia się, uczący się mierzy się bowiem jednocześnie z innymi zadaniami: zbudowaniem relacji z innymi uczestnikami, refleksją nad swoją tożsamością, zdefiniowaniem nowych ról społecznych dla siebie i innych, znalezieniem sensu dla swoich działań interakcyjnych w danym mikrokontekście. Istotne jest przy tym zauważenie, że wpływ na linii kontekst - jednostka - proces uczenia się nie jest jednostronny, ale obustronny, również jednostka może wpływać na kontekst i go zmieniać. Wśród metod badawczych szczególnie odpowiadających takiemu podejściu wymienia się badanie w działaniu, studium przypadku, metody etnograficzne i narracyjne.

Zastanawiając się nad tym, co nowego podejścia ekologiczne mogą wnieść do badań glottodydaktycznych, należy zauważyć, że nie mówimy o zupełnie nowym paradygmacie badawczym, dopracowanej teorii czy nowej metodzie nauczania/uczenia się, ale raczej o przesunięciach znaczeniowych w obrębie znanych już pojęć i terminów, o inaczej rozmieszczonych akcentach i o innych układach treści, które, zgodnie z zasadą emergencji, prowadzą do nowych znaczeń. Jak podkreśla van Lier (2004: 224): „Chodzi po prostu o pewien sposób myślenia o nauczaniu i uczeniu się w całej ich złożoności, o sposób patrzenia na język jako narzędzie o różnych możliwościach użycia i kluczowy komponent we wszystkich znaczeniowo istotnych działaniach człowieka" ${ }^{13}$.

${ }^{12}$ Effectivement, la perspective écologique, telle qu'elle vient d'être présentée, consiste à prendre au sérieux et à développer de façon systématique et approfondie l'affirmation générique et communément admise selon laquelle « le contexte est important ». Qui veut s'engager dans une approche écologique de la seconde langue fait de la description du contexte et de ses rapports avec les processus d'acquisition l'objet central de sa propre recherche (Pallotti, 2002: 167).

${ }^{13}$ It is just a way of thinking about teaching and learning in all its complexity, a way of looking at language as a tool of many uses, and as a key component of all human meaning-making activity. 


\section{W odpowiedzi na tytułowe pytanie}

Na nieco inne pytanie niż tytułowe, a mianowicie: Czy propozycja ekolingwistyki dla glottodydaktyki jest godna uwagi? Magdalena Steciąg (2014: 60) odpowiada twierdząco, wymieniając trzy argumenty:

- jest to zachęta do inspirującej badaczy refleksji teoretycznej;

- pozwala w sposób krytyczny zweryfikować pewne obiegowe opinie (np. najlepszym nauczycielem jest native speaker) oraz w pewnym sensie ujawnia ideologiczne podstawy niektórych działań dydaktycznych;

- zachęca do łączenia kształcenia językowego z problemami ponowoczesnej współczesności.

Trudno nie zgodzić się z takim punktem widzenia, jednak pytając: Czy jesteśmy gotowi na ekoglottodydaktykę? zarówno w sensie badawczym, jak i aplikacyjnym myślę już o kroku następnym, którym jest wdrożenie perspektywy ekologicznej w badania i praktykę glottodydaktyczną w polskim kontekście edukacyjnym. Ostatni regionalny kongres M iędzynarodowej Federacji Nauczycieli Języka Francuskiego (fr. Fédération Internationale des Professeurs de Français) w Kioto w 2017 roku przebiegał pod hasłem Écologie du français et diversité des langues $^{14}$ i nieprzypadkowo odbywał się w 20 . rocznicę podpisania w tym właśnie mieście protokołu w sprawie przeciwdziałania globalnemu ociepleniu. Przewodniczący FIPF J ean-M arc Defays entuzjastycznie pisze o „ekologicznej, trwałej, odnawialnej dydaktyce" (2017, on-line) ${ }^{15}$, ale czy są ku temu realne przesłanki? Zastrzegam od razu, że odpowiadam wyłącznie we własnym imieniu: otóż uważam, że nie jesteśmy gotowi na przyjęcie perspektywy ekologicznej w teoretycznej i praktycznej odsłonie dydaktyki języków obcych ze wszystkimi jej konsekwencjami, o których była mowa uprzednio. Wynika to z kilku powodów:

- głębokie osadzenie myślenia glottodydaktycznego w oddzielnie funkcjonujących „przegródkach" zamiast myślenia holistycznego: procesy nauczania-uczenia się języków są doskonale opisaną strukturą, w której, teoretycznie, wszystko jest połączone (kompetencje, umiejętności, kontekst, uczący się itp.), ale de facto funkcjonuje i jest badane odrębnie;

- różnojęzyczność jest wprawdzie dobrze rozpoznanym konceptem teoretycznym (zob. Kucharczyk, 2018), ale daleko jej do satysfakcjonujących wdrożeń praktycznych, nie mówiąc już o odwoływaniu się do pojęć typu „ekosystem językowy”, kiedy nadal używamy określeń „języki

${ }^{14}$ Ekologia języka francuskiego i różnorodność językowa.

15 «Une didactique écologique, durable, douce » (Defays, 2017, on-line). 
tercjarne” lub je numerujemy w kolejności „ważności” (np. w systemie francuskim Langue vivante 1, Langue vivante 2);

- silne przywiązanie do teorii kognitywnych osadzonych w dualizmach typu input-output, które nie pozostawiają miejsca dla wspomnianych wcześniej afordancji;

- nadawanie priorytetu działaniom językowym uczących się a marginalizowanie kwestii relacyjnych i tożsamościowych;

- postrzeganie kontekstu jako tła dla działań językowych;

- ograniczony zasięg badań jakościowych typu etnograficznego czy narracyjnego uznawanych za mniej „naukowe” i obarczone błędem nadmiernego subiektywizmu.

Natomiast od strony wdrożenia do praktyki szkolnej perspektywy ekologicznej widzę dwie główne przeszkody:

- programy kształcenia przyszłych nauczycieli są przeładowane teoretyczną wiedzą akademicką, często "mozaikową" (Gołębniak, Krzychowiak, 2015) i oderwaną od rzeczywistości szkolnej, która nie przyczynia się do myślenia o nauczaniu/uczeniu się jako całościowym procesie dydaktyczno-psychologiczno-pedagogicznym, zanurzonym w specyficznym kontekście edukacyjnym ${ }^{16}$;

- testocentryzm polskiej szkoły narzucający ciasny gorset każdej lekcji języka obcego.

To z pewnością nie wyczerpuje listy, ale wskazuje na rozziew w myśleniu ekologicznym o nauczaniu / uczeniu się języków a myśleniem nawet w najbardziej aktualnych teoriach uczenia się. A zatem nie, moim zdaniem, nie jesteśmy gotowi na eko-glottodydaktykę. Narzuca się zatem kolejne pytanie: Czy chcemy to zmienić? Odpowiedzi na nie dostarczą dalsze badania i analizy, których z pewnością nie zabraknie.

\section{BIBLIOGRAFIA}

Bronfenbrenner U. (1979), The ecology of human development: Experiments by nature and design. Cambridge, Massachusetts, London : Harvard University Press.

Calvet L.-J. (1999), Pour une écologie des langues du monde. Paris: Plon.

\footnotetext{
${ }^{16}$ Początki zmian w tym zakresie są już obecne w polskim piśmiennictwie glottodydaktycznym (zob. np. Lankiewicz, 2015; Szymankiewicz, 2017), ale pozostaje jeszcze daleka droga do ich rzeczywistych wdrożeń w programy kształcenia przyszłych nauczycieli.
} 
Chen S. (2016), Language and ecology: A content analysis of ecolinguistics as an emerging research field. „Ampersand", nr. 3, s. 108-116. Online: https:// www.sciencedirect.com/journal/ampersand/vol/3/suppl/C [DW 15.06.2019].

Costa J. (2008), Langues et cultures régionales, langues vivantes étrangères. Quels enjeux pour une convergence didactique ? "Les Cahiers de l'Acedle", nr 5, s. 109-128.

Czerepaniak-Walczak M. (2006), Pedagogika emancypacyjna, rozwój świadomości krytycznej człowieka. Gdańsk: Gdańskie Wydawnictwo Psychologiczne. Defays J.M. (2017), Une didactique des langues et cultures écologique, dutable, douce? „Le français dans le monde”, nr 414. Online: http://jea nmarcdefays.be/ une-didactique-des-langues-et-des-cultures-ecologiqu e-durable-douce/ [DW 20.08.2019].

Dotov D.G., Nie L., de Wit M .M . (2012), Zrozumieć afordancję: przegląd badań nad główną tezą Jamesa J. Gibsona. „Avant”, nr 3/2, s. 282-295 (przekład:

D. Lubiszewski, N. Strehlau).

Giroux H.A., Witkowski L. (red.) (2010), Edukacja i sfera publiczna, idee i doświadczenia pedagogiki radykalnej. Kraków: Oficyna Wydawnicza Impuls. Gołębniak B.D., Krzychowiak S. (2015), Akademickie kształcenie nauczycieli w Polsce - raport z badań. „Rocznik Pedagogiczny”, nr 38, s. 97-112.

Hagège C. (1985), L'homme de paroles. Paris: Fayard.

Hahn Y., Rodriguez-Kaarto T.J. (2015), Designing for social integration: an ecological approach to language learning. "Nordes” $\mathrm{nr} 6$, s. 1-8. Online: https://archive.nordes.org/index.php/n13/issue/view/11 [DW 15.07. 2019].

Gibson J.J. (1986), The Ecological Approach to Visual Perception. Hillsdale, New Jersey: Lawrence Erlbaum.

Haugen E. (1972), The Ecology of Language. Stanford University Press: Stanford, CA. Kramsch C., Steffensen S.V. (2008), Ecological perspectives on second language acquisition and socialization, (w:) Duff P.A., Hornberger N.H. (red.), Encyclopedia of Language and Education, 2nd Edition, nr 8, s. 17-28. Online: https://www.researchgate.net/publication/226707454_Ecological_Perspec tives_on_Second_Language_Acquisition_and_Socialization [DW: 15.07.2019]. Krawczak M. (2017), Poznańska Szkoła Ekolingwistyki. „Scripta Neophilologica Posnaniensia". t. XVII, s. 145-192. Online: https://pressto.amu.edu.pl/ index.php/snp/article/view/13280/12990 [DW 28.08.2019].

Kucharczyk R. (2018), Nauczanie języków obcych a dydaktyka wielojęzyczności (na przykładzie francuskiego jako drugiego języka obcego). Lublin: Werset. Lankiewicz H. (2015), Teacher language awareness in the ecological perspective. A collaborative inquiry based on languaging. Gdańsk: Wydawnictwo Uniwersytetu Gdańskiego. 
Larsen-Freeman D. (1997), Chaos/complexity science and second language acquisition. „Applied Linguistics”, nr 18 (2), s. 141-165.

Lechevrel N. (2010), L'écologie du langage d'Einar Haugen. „Histoire Épistémologie Langage", nr 32 (2), s. 151-166. Online: https:// www.persee.fr/ doc/hel_0750-8069_2010_num_32_2_3192 [DW 20.08.2019].

van Lier L. (2004), The Ecology and Semiotics of Language Learning: A Sociocultural Perspective. Boston: Kluwer Academic.

van Lier L. (2010), The ecology of language learning: Practice to theory, theory to practice. "Procedia Social and Behavioral Sciences", nr 3, s. 2-6.

Longhi J. (2012), Compte-rendu de : "Les Approches écologiques en linguistique » (N. Lechrevel, 2010) : pour une linguistique « verte » ? "Corela. Cognition, Représentation, Langage", nr 10 (1), s. 1-5. Online : http://jo urnals.openedition.org/corela/2674 [DW 20.08.2019]

Matczak P. (2000), Problemy ekologiczne jako problemy społeczne. Poznań: Wydawnictwo Naukowe UAM, Seria Socjologia nr 27.

Moore J. (2015), Capitalism in the Web of Life Ecology and the Accumulation of Capital. London/New York: Verso.

M ühlhäusler P. (1996), Linguistic Ecology. Language Change and Linguistic Imperialism in the Pacific Region. Routledge: London.

M ühlhäusler P. (2002), Why one cannot preserve languages (but can preserve language ecologies), (w:) Bradley D., Bradley M. (red.), Language endangerment and language maintenance. London: Routledge Curzon, s. 34-39.

Pallotti G. (2002), La classe dans une perspective écologique de l'acquisition. „Acquisition et interaction en langue étrangère”, nr 16, s. 165-197. Online: http://journals.openedition.org/aile/1395 [DW 30.04.2019].

Steffensen S. V., Fill, A. (2014), Ecolinguistics: the state of the art and future horizons. (w:) Steffensen, S. V., Fill, A. (red.), „Language Sciences” nr 41, Ecolinguistics: The ecology of language and science, s. 6-25.

Steciąg M . (2014), Glottodydaktyka w ujęciu ekolingwistycznym. „Acta Universitatis Lodziensis. Kształcenie polonistyczne cudzoziemców", nr 21, s. 51-62. Szymankiewicz K. (2017), Przyszli nauczyciele języków obcych na drodze budowania kompetencji zawodowej. Refleksja - uczenie się - rozwój. Warszawa/Lublin: Instytut Romanistyki UW/Wydawnictwo Werset.

Tyburski W. (2017), M yśl humanistyczna na rzecz ochrony środowiska przyrodniczego. „Ruch Filozoficzny”, nr 73 (1), s. 52-65.

Walewicz P. (2019), Koncepcje antropocenu i kapitalocenu a ekopedagogika. „Przegląd Pedagogiczny", nr 1, s. 57-67.

Weiner J. (2019), Rozkosze różnorodności. „Pismo. Magazyn opinii”, nr 8 (20), S. $18-25$. 